\title{
An Investigation of Thermal Shock in Porous Clay Ceramics
}

\author{
F. W. Nyongesa, ${ }^{1,2}$ N. Rahbar, ${ }^{1,3}$ S. K. Obwoya, ${ }^{1,4}$ J. Zimba, ${ }^{1,5}$ \\ B. O. Aduda, ${ }^{1,2}$ and W. O. Soboyejo ${ }^{1,6}$ \\ ${ }^{1}$ Princeton Institute for the Science and Technology of Materials (PRISM), Princeton University, 70 Prospect Street, \\ Princeton, NJ 08540, USA \\ ${ }^{2}$ Department of Physics, University of Nairobi, P.O. Box 30197, Nairobi, Kenya \\ ${ }^{3}$ Department of Civil and Environmental Engineering, University of Massachusetts Dartmouth, North Dartmouth, MA 02747, USA \\ ${ }^{4}$ Department of Physics, Kyambogo University, P.O. Box 1 Kyambogo, Kampala, Uganda \\ ${ }^{5}$ Mintek, Advanced Materials Division, MINTEK, 200 Hans Strijdom Drive, Private Bag X3015, Randburg 2125, South Africa \\ ${ }^{6}$ Department of Mechanical and Aerospace Engineering, Princeton University, Olden Street, Princeton, NJ 08544, USA
}

Correspondence should be addressed to S. K. Obwoya, ksobwoya@yahoo.co.uk

Received 16 February 2011; Accepted 8 March 2011

Academic Editors: A. J. Chamkha, C. W. Lim, and G.-J. Wang

Copyright ( $) 2011$ F. W. Nyongesa et al. This is an open access article distributed under the Creative Commons Attribution License, which permits unrestricted use, distribution, and reproduction in any medium, provided the original work is properly cited.

\begin{abstract}
The thermal shock resistance of porous ceramic materials is often characterized by the Hasselman parameters. However, in other scenarios, the room-temperature residual strengths after thermal shock are also used to quantify the damage due to thermal shock. This paper attempts to link the measured residual strengths to the dominant crack features that are introduced due to thermal shock in porous clay ceramics produced by the sintering of clay powders with well-controlled size ranges. Residual strength estimates from bend tests are compared with fracture mechanics predictions. The implications of the residual strength results are then discussed for the characterization of damage due to thermal shock.
\end{abstract}

\section{Introduction}

The classical theory on the thermal shock behaviour of brittle ceramics was established by Hasselman in 1969 [1,2]. He showed that opposing property requirements prevail, depending on whether the material is required to be resistant to crack initiation (for which high strength and low stiffness are essential), or resistant to strength degradation, following a severe thermal shock (in which case, low strength and high stiffness are beneficial). Furthermore, the room-temperature residual strengths after thermal shock are also used to quantify the damage due to thermal shock [2-5]. Since Evans and Charles [6] applied fracture mechanics to the modeling of thermal shock in 1975, resistance-curve (Rcurve behavior) has been used extensively to model stable crack growth behavior in the ceramic community [7-11]. $\mathrm{Lu}$ and Fleck [12] have also developed a rigorous theoretical framework for the modeling of thermal shock while Soboyejo et al. [13] and Baker et al. [14] have explained crack growth resistance under thermal shock loading with cracktip shielding concepts.

Porous clay ceramics form an important class of refractory materials that are used widely as thermal insulators in high-temperature applications such as in kilns, furnaces, and domestic charcoal stoves (jikos). In such applications, these materials are often exposed to cyclic thermal stresses and, at times, even severe thermal shocks that can result in significant strength degradation $[15,16]$. There is, therefore, a need to relate the thermal shock behavior to the room-temperature strength degradation that is often observed in clays after thermal shock. This paper presents the results of a combined experimental and theoretical study that presents some new insights into how to relate damage due to thermal shock to the degradation of roomtemperature strength of clay ceramics with well-controlled porosities. The implications of the results are discussed for the design of porous clay ceramics for refractory applications. 
TABLE 1: Chemical composition of the clay raw material.

\begin{tabular}{lccccccccc}
\hline Component & $\mathrm{SiO}_{2}$ & $\mathrm{Al}_{2} \mathrm{O}_{3}$ & $\mathrm{CaO}$ & $\mathrm{Fe}_{2} \mathrm{O}_{3}$ & $\mathrm{MgO}$ & $\mathrm{K}_{2} \mathrm{O}$ & $\mathrm{Na}_{2} \mathrm{O}$ & $\mathrm{TiO}_{2}$ & $* \mathrm{LOI}^{2}$ \\
\hline Fraction (wt. \%) & 67.20 & 18.20 & 0.31 & 2.83 & 0.36 & 0.98 & 0.19 & 1.38 & 8.10 \\
\hline
\end{tabular}

${ }^{*}$ LOI: loss on ignition.

\section{Experimental Procedures}

2.1. Materials Processing. The clay raw materials used in this study were obtained from Mukono District in Uganda. The chemical composition of the clays is presented in Table 1. Four (4) types of test samples (with particle sizes ranges of 45-63 $\mu \mathrm{m}, 63-90 \mu \mathrm{m}, 90-125 \mu \mathrm{m}$, and 125-250 $\mu \mathrm{m}$ ) were prepared by ball milling and sieving. The sieved powders were then compacted into rectangular test specimens with dimensions of $6.5 \pm 0.1 \mathrm{~mm} \times 6.5 \pm 0.1 \mathrm{~mm} \times 52 \pm$ $0.1 \mathrm{~mm}$ under $150 \mathrm{MPa}$ pressure using a stainless die. The test samples were then fired to $1,300^{\circ} \mathrm{C}$ in an electric furnace at a heating rate of $5^{\circ} \mathrm{C} \mathrm{min}^{-1}$. A holding time of 3 hours was applied at the sintering temperature before the furnace was switched off to allow the samples to cool down to roomtemperature at an initial rate of $5^{\circ} \mathrm{C} \mathrm{min}^{-1}$.

2.2. Porosity and Strength Measurements. The bulk density and volume fraction porosity of the sintered samples were measured using Archimedes' immersion technique, which involved boiling the samples in water for 3 hours. The flexural strengths (MORs) of the rectangular test specimens were determined under three-point bend test using an Instron Model 8872 servohydraulic testing machine (Instron, Canton, MA) with cross-head speed of $0.5 \mathrm{~mm} \mathrm{~min}^{-1}$ and a loading span $(S)$ of $35 \pm 0.1 \mathrm{~mm}$. MOR was evaluated from the following expression [17]:

$$
\mathrm{MOR}=\frac{3 P S}{2 B^{2} W}
$$

where $P$ is the load at failure, $S$ is the span; $B$ and $W$ are the respective breath and width of the rectangular specimens. Fracture toughness $\left(K_{\mathrm{Ic}}\right)$ tests were performed on singleedge notched-bend (SENB) specimens that were loaded monotonically to failure at a loading rate of $0.5 \mathrm{~mm} \mathrm{~min}^{-1}$, with a loading span of $35 \pm 0.1 \mathrm{~mm}$. An initial notch, with a notch-to-width ratio $(a / W)$ of $\sim 0.25$, was introduced at the center of the specimens. Fracture toughness, $K_{\text {Ic }}$, was determined from $(2)[18,19]$

$$
K_{\mathrm{Ic}}=\frac{P_{Q} S}{B W^{3 / 2}} \times f\left(\frac{a}{W}\right)
$$

where $P_{Q}$ is the failure load, $a$ is the crack length (depth of the notch), and $f(a / W)$ is the compliance function.

2.3. Thermal Shock. The thermal shock resistance was determined by measuring the retention of the flexural strength of water-quenched (cold-shocked) samples. The samples were first heated in a furnace to $1,000^{\circ} \mathrm{C}$ at the rate of $10^{\circ} \mathrm{C} \mathrm{min}{ }^{-1}$.
A holding time of 30 min was then applied to the samples before quenching (cold-shocking) them into a container of water that was maintained at $5.0^{\circ} \mathrm{C}$. The samples were then dried in an oven for $30 \mathrm{mins}$ at $110^{\circ} \mathrm{C}$. The dried samples were either tested in bending to determine their residual strengths or quenched further to establish the effects of quenching on their residual strengths. This was continued for 5 cycles.

The crack/microstructure interactions associated with cold-shock were observed in a scanning electron microscope (Philips XL30 FEG-SEM) equipped with energy dispersive $\mathrm{X}$-ray spectroscopy (EDS) capabilities. The latter was used to characterize the local chemical compositions of the microstructural constituents. Some samples were also etched in concentrated hydrofluoric acid (HF 48\%) for 3 minutes to reveal the underlying microstructures. These were rinsed thoroughly in water and ultrasonically cleaned in acetone before scanning electron microscopy (SEM) analysis. To avoid charging effects from the nonconducting ceramic surface, the samples were coated with a thin layer $(\sim 0.045 \mathrm{k} \AA)$ of gold.

\section{Results}

3.1. Microstructure. The porous structure and the microstructure of the sintered clay samples are presented in Figures $1(\mathrm{a})-1(\mathrm{~d})$. The samples produced by the sintering of small particles with diameters of $\sim 45-63 \mu \mathrm{m}$ show nearly spherical pores (Figure 1(a)) with an overall porosity of $\sim 8.8 \%$ (Table 2 ). However, the samples produced from the larger particle sizes $(125-255 \mu \mathrm{m})$ show a network of interconnected pores (Figure 1(b)) with a higher level of porosity $(18.3 \%)$, as shown in Table 2 . Sample porosity also increased with increasing particle size range (Table 2).

Etched sections of the samples (Figures 1(c) and 1(d)) show large and well-defined mullite needles in a matrix of silica. The mullite needles have lengths of $\sim 1.5 \pm 0.3 \mu \mathrm{m}$ in samples processed from finer particle sizes $(45-63 \mu \mathrm{m})$ and lengths of $\sim 5.5 \pm 1.5 \mu \mathrm{m}$ in samples processed from coarser particle sizes $(125-255 \mu \mathrm{m})$ as indicated in Table 3.

3.2. Porosity and Room-Temperature Mechanical Properties. The room-temperature mechanical properties of the clay samples are summarized in Table 2. Figure 2(a) shows the dependence of the modulus of rupture (MOR) on porosity. The MOR decreases exponentially with increasing porosity. Similarly, the fracture toughness also decreases exponentially with increasing porosity (Figure 2(b)). Similar trends have been observed by other researchers [20,21], and these trends of behaviour are generally attributed to stress concentration phenomena $[22,23]$. 


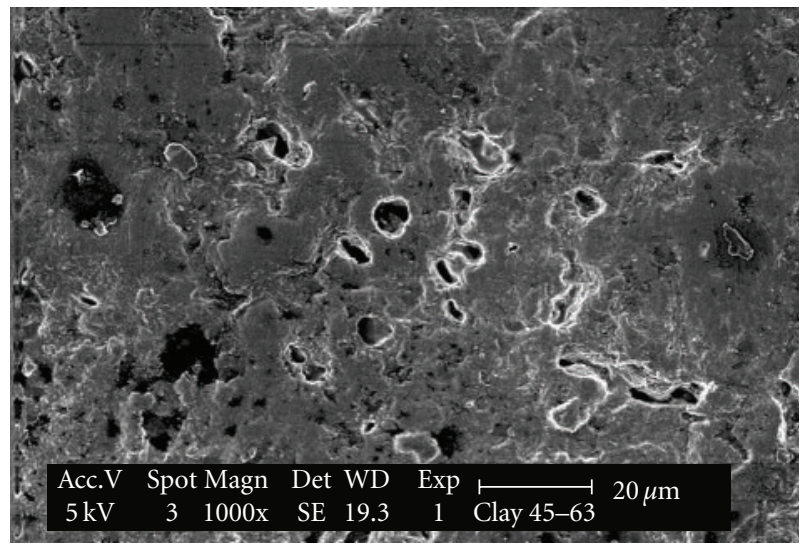

(a)

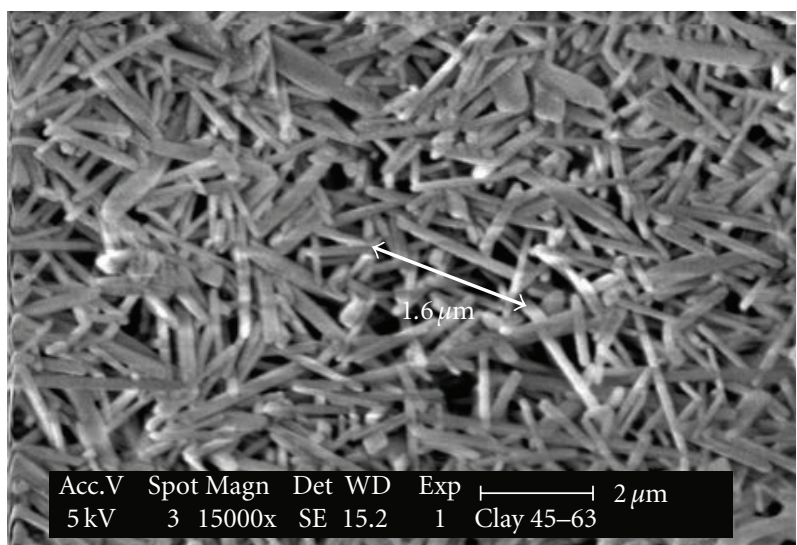

(c)

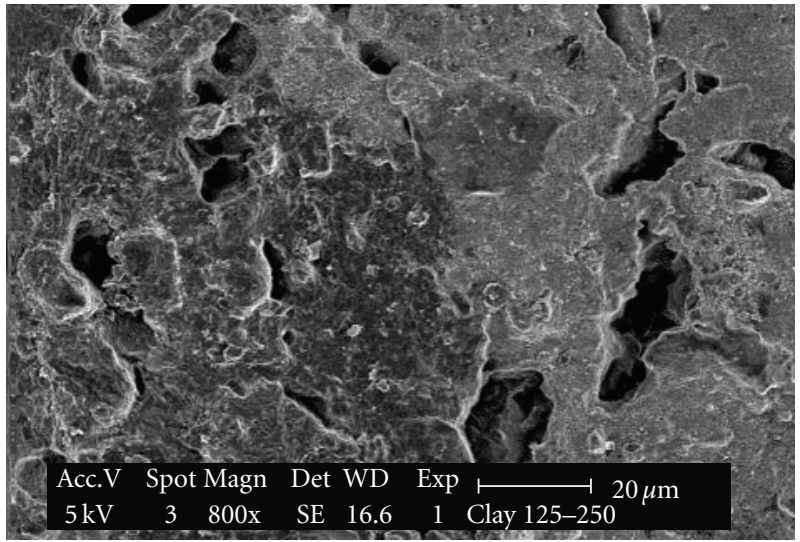

(b)

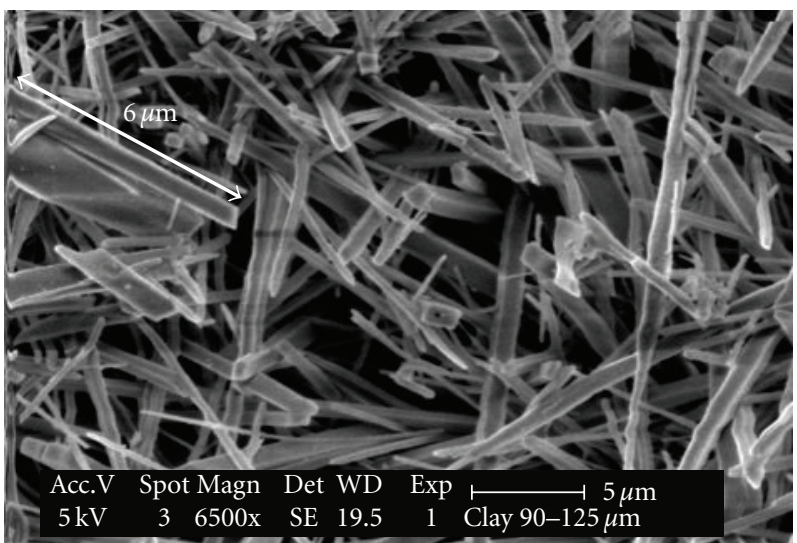

(d)

Figure 1: Structure of sintered clay samples: (a) pore structures after sintering of powders with size ranges between $45-63 \mu \mathrm{m}, P=8.8 \%$; (b) size ranges between 125-255 $\mu \mathrm{m}$ showing bimodal and interconnected pore structure, $P=18.3 \%$; (c) etched sections of samples from particle size ranges $45-63 \mu \mathrm{m}$ showing small mullite needles (1-2 $\mu \mathrm{m})$ and (d) etched section of samples from particle size ranges $125-255 \mu \mathrm{m}$ showing large mullite crystals $(5-7 \mu \mathrm{m})$

TABLE 2: Mechanical properties of clay ceramics.

\begin{tabular}{lccccc}
\hline Particle size range $(\mu \mathrm{m})$ & Porosity $(\%)$ & Bulk density, $\rho\left(\mathrm{g} \mathrm{cm}^{-3}\right)$ & Fracture toughness, $K_{\mathrm{Ic}}(\mathrm{MPa} \sqrt{\mathrm{m}})$ & $\mathrm{MOR}(\mathrm{MPa})$ & $E(\mathrm{GPa}) \pm 5 \%$ \\
\hline $45-63$ & $8.8 \pm 0.6$ & $2.5 \pm 0.1$ & $2.1 \pm 0.1$ & $19.4 \pm 4.0$ & 54.06 \\
$63-90$ & $9.9 \pm 0.4$ & $2.4 \pm 0.1$ & $1.2 \pm 0.3$ & $11.1 \pm 3.2$ & 53.15 \\
$90-125$ & $14.0 \pm 1.5$ & $2.3 \pm 0.1$ & $0.8 \pm 0.2$ & $6.9 \pm 1.0$ \\
$125-250$ & $18.3 \pm 2.6$ & $1.9 \pm 0.1$ & $0.6 \pm 0.1$ & $5.8 \pm 1.5$ & 46.99 \\
\hline
\end{tabular}

TABLE 3: Microstructural details of the clay ceramics.

\begin{tabular}{lccr}
\hline Particle size range $(\mu \mathrm{m})$ & Length $(\mathrm{l})$ of mullite needles $(\mu \mathrm{m})$ & Mullite width $(\mathrm{w})(\mu \mathrm{m})$ & Aspect ratio $(1 / \mathrm{w})$ \\
\hline $45-63$ & $1.50 \pm 0.30$ & $0.16 \pm 0.08$ & $9.03 \pm 0.38$ \\
$63-90$ & $2.60 \pm 0.40$ & $0.25 \pm 0.05$ & $10.4 \pm 0.45$ \\
$90-125$ & $3.25 \pm 0.25$ & $0.35 \pm 0.15$ & $9.28 \pm 0.40$ \\
$125-250$ & $5.50 \pm 1.50$ & $0.60 \pm 0.20$ & $9.17 \pm 1.70$ \\
\hline
\end{tabular}


TABLE 4: Measured residual strengths of clay ceramics after thermal shock.

\begin{tabular}{lcccc}
\hline Particle size range $(\mu \mathrm{m})$ & \multicolumn{3}{c}{ Residual strength, $\sigma_{\text {meas }}(\mathrm{MPa})$} & $N=4$ \\
\hline $45-63$ & $N=1$ & $N=2$ & $N=3$ & 7.90 \\
$63-90$ & 12.21 & 9.57 & 7.37 & 6.82 \\
$90-125$ & 8.39 & 7.56 & 5.96 & 5.71 \\
$125-250$ & 6.64 & 5.73 & 4.92 & 5.29 \\
\hline
\end{tabular}

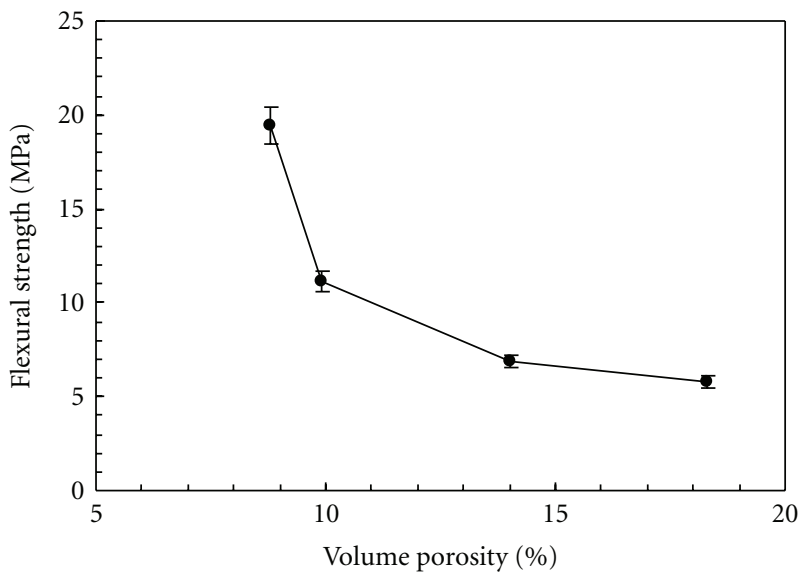

(a)

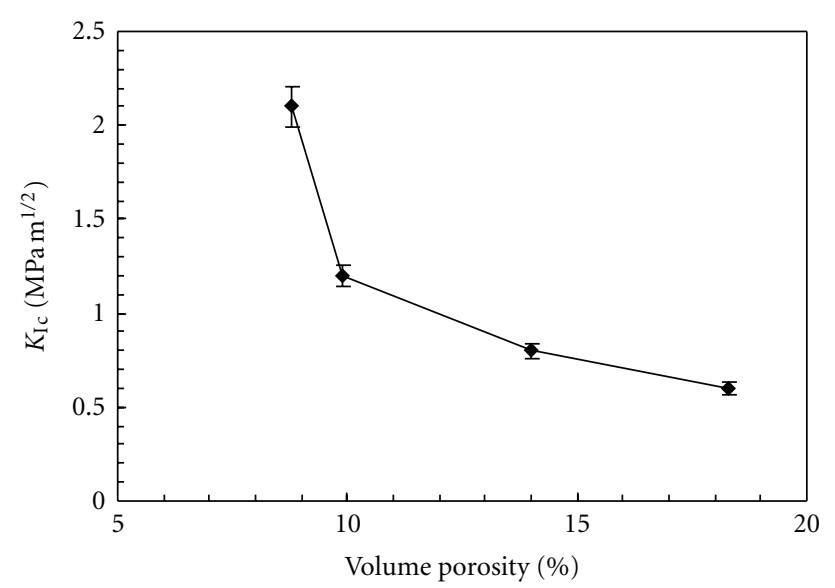

(b)

FIgURE 2: The effects of porosity on room-temperature mechanical properties: (a) Flexural strength (MOR) and (b) Fracture toughness $K_{\text {Ic }}$.

3.3. Residual Strengths and Cold Shock. The dependence of residual flexural strengths on number of shock cycles is presented in Table 4 and shown graphically in Figure 3. The largest changes in strength in all samples were observed after the first cycle. Thereafter, smaller incremental changes in the residual strength were observed as the number of shock cycles increased. The highest initial strengths and the highest subsequent drops in strength were observed in the samples processed from particles with diameters of $45-63 \mu \mathrm{m}$. These failed consistently after 3 shock cycles. Furthermore, the

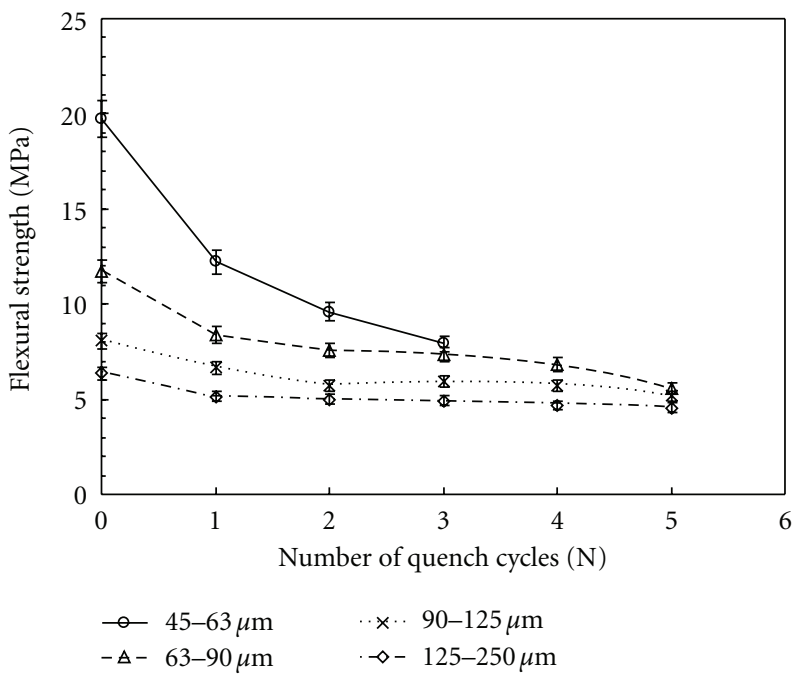

FIGURE 3: Flexural strength of the clay samples as a function of quench cycles.

residual strengths decreased with increasing particle size ranges, though the fractional changes in strength were lower as the number of shock cycles increased. The samples produced by the sintering of the larger particle sizes generally survived for up to 5 cold-shock cycles.

3.4. Crack/Microstructure Interactions. Typical crack/microstructure interactions observed in the thermally shocked samples are presented in Figures 4(a)-4(c). These show the growth of dominant cracks, with uncracked bridging ligaments behind the crack tip. Viscoelastic crack bridging [24] acts to restrict the opening of the cracks, and thereby promote the shielding of cracks. After 1 cold quench cycle, clay samples with finer particle sizes $(45-63 \mu \mathrm{m})$ were observed to have more viscous bridging ligaments than those produced from larger particles sizes (125-255 $\mu \mathrm{m})$. This is shown clearly in Figures 4(a) and 4(b); however, the incidence of ligament bridging decreases with increasing number of shock cycles, as shown in Figure 4(c).

After cold-shock, the other toughening mechanisms observed in the room-temperature flexural specimens are presented in Figures 5(a)-5(c). These show evidence of toughening by crack-tip blunting (cracks being arrested by pores, Figure 5(a)), crack deflection and crack branching (Figure 5(b)), and secondary microcracking (Figure 5(c)). 


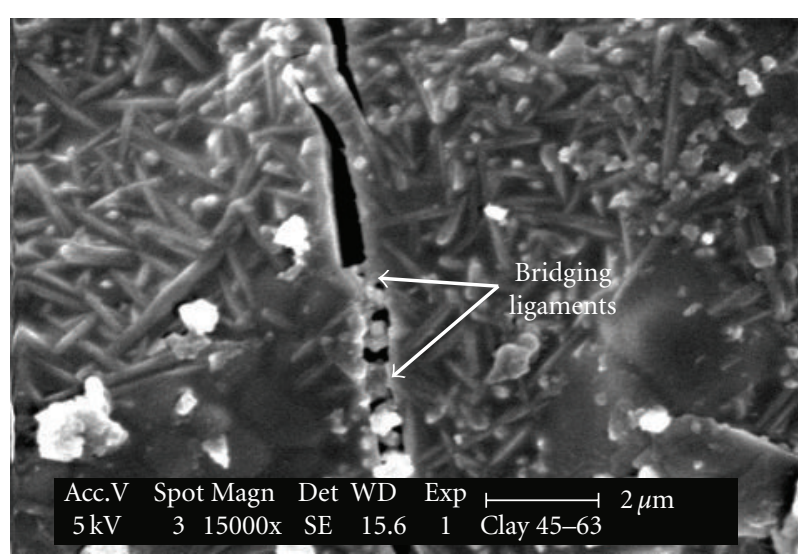

(a)

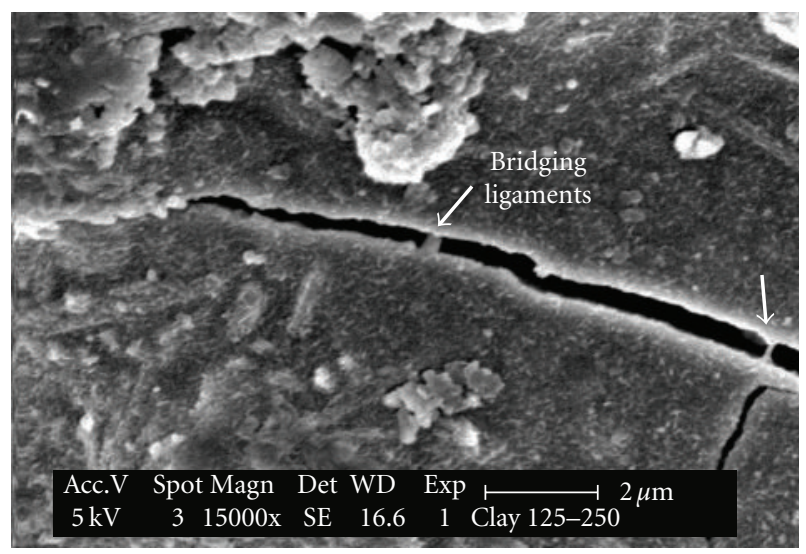

(b)

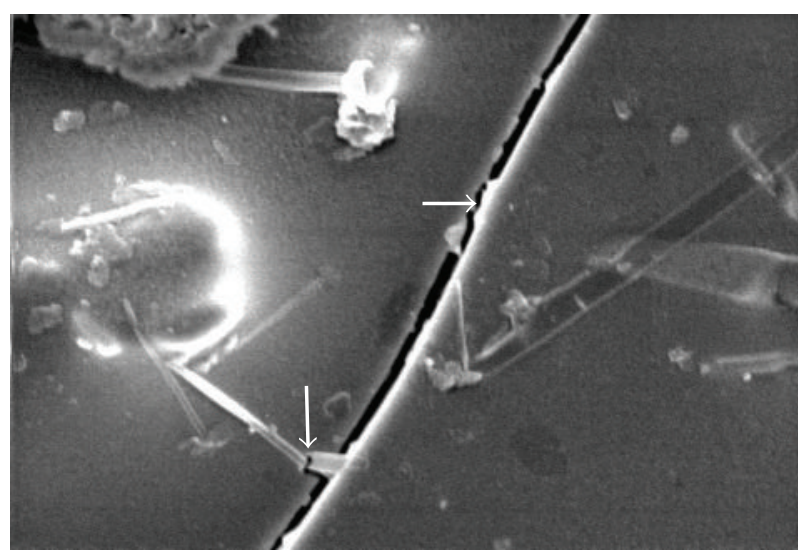

(c)

FIGURE 4: Schematic of observed toughening mechanisms due to viscous bridging in clay samples: (a) $45-63 \mu \mathrm{m}, N=1$, showing viscous bridging ligaments at the crack tip; (b) $125-255 \mu \mathrm{m}, N=1$, showing less ligament bridging at the crack tip compared to (a); (c) $45-63 \mu \mathrm{m}, N=2$, showing shattered bridging ligaments due to thermal shock.

\section{Discussions}

4.1. Fracture Modes and Residual Strength Predictions. Typical fracture modes observed in the flexural specimens after cold-shocking and room-temperature fracture (under three-

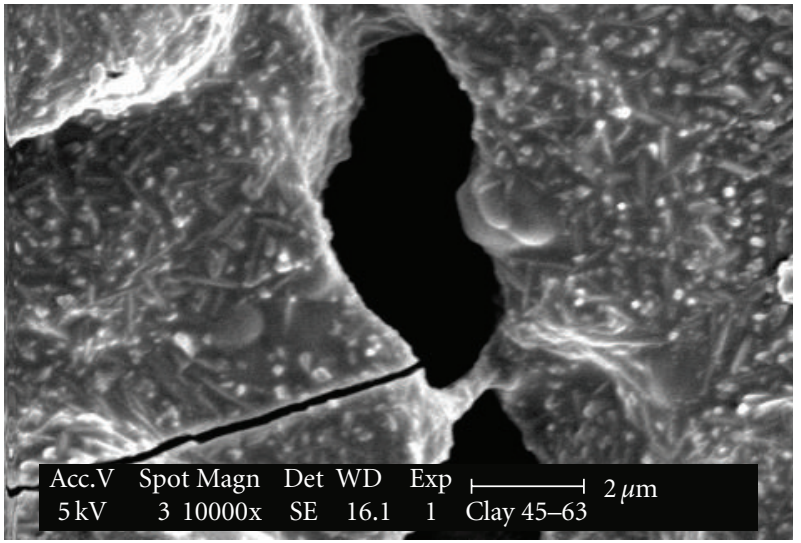

(a)

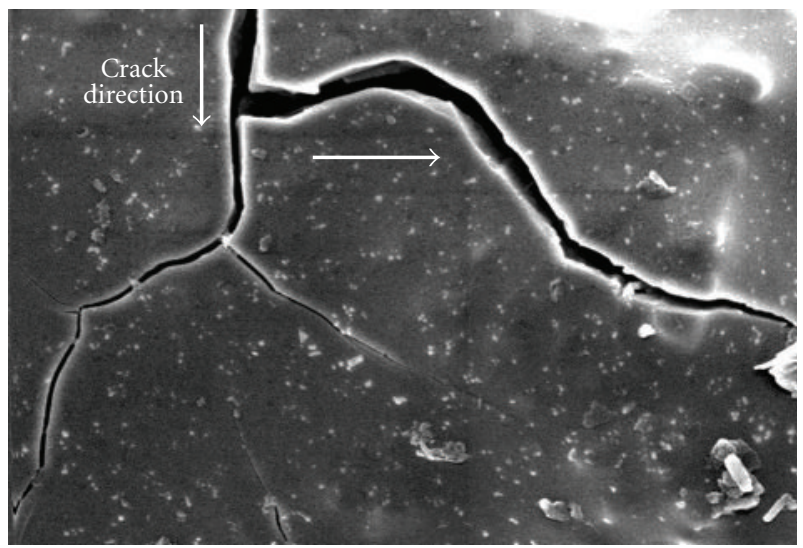

(b)

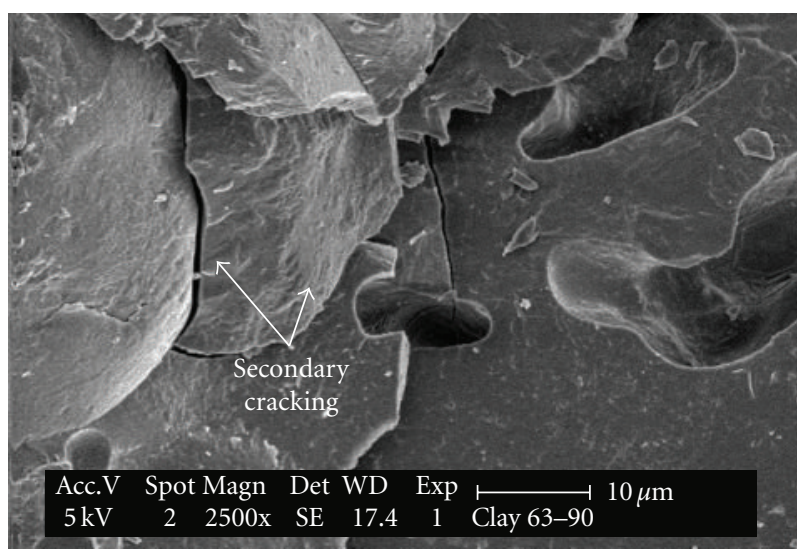

(c)

FIGURE 5: Schematic of observed toughening mechanisms in clay samples due to (a) crack blunting by a pore, (b) crack deflection and crack branching, and (c) fractured surface showing intergranular fracture and secondary crackings.

point loading) are presented in Figures 6(a)-6(d). These show clearly that final fracture initiated largely from corner cracks that were introduced into the specimens during thermal shock. Such cracks are found in a large number of engineering structures and components [7], where stress 


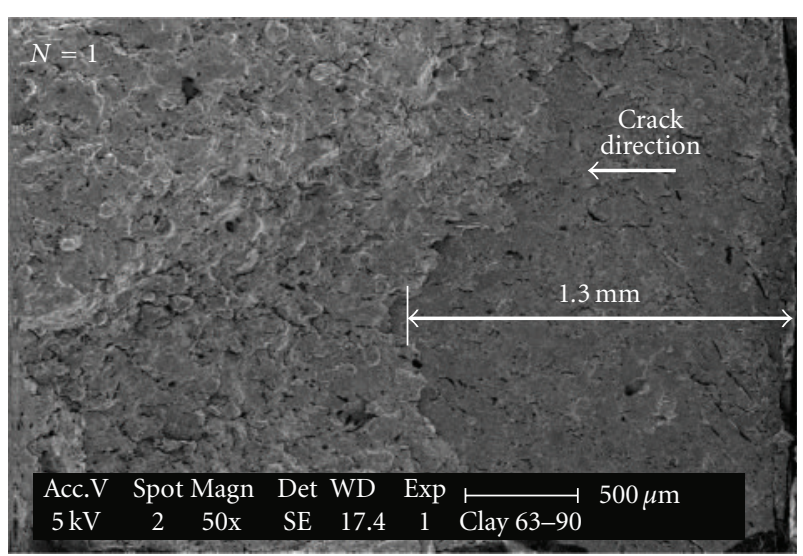

(a)

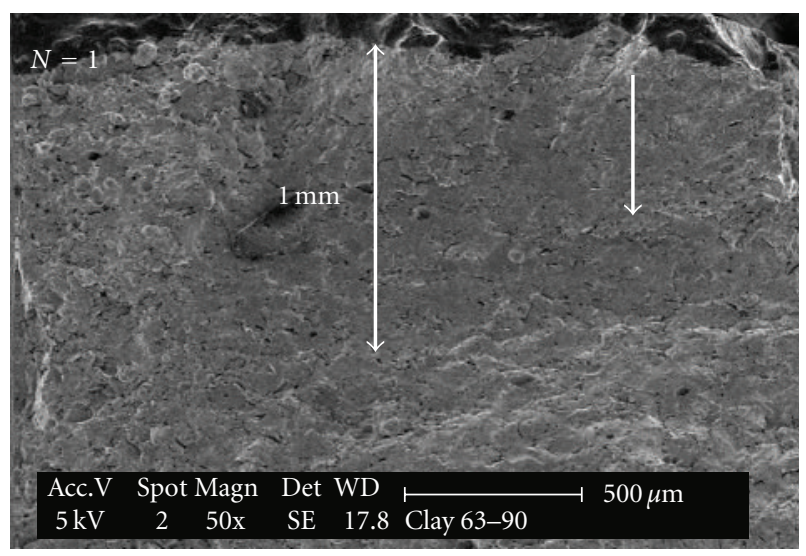

(c)

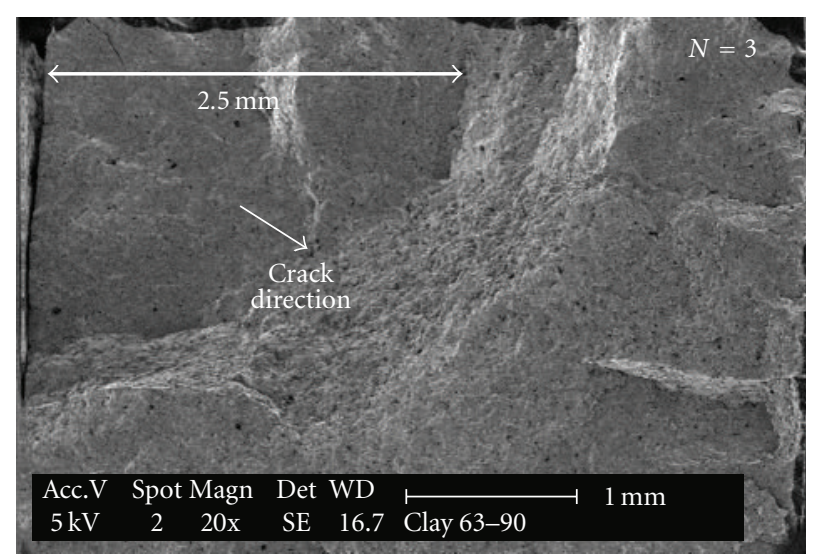

(b)

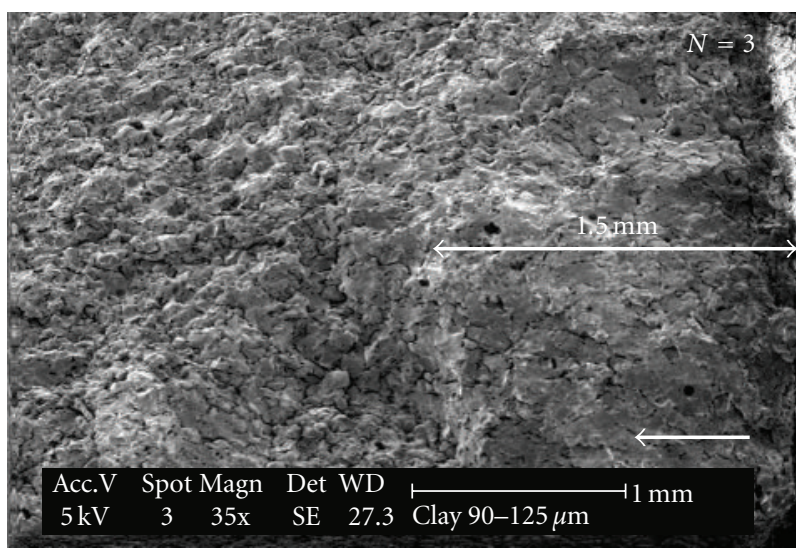

(d)

FIGURE 6: Schematic of fractured surfaces in sintered clay samples showing crack lengths after thermal shock: (a) $63-90 \mu \mathrm{m}, N=1, a=$ $1.3 \mathrm{~mm}$; (b) 63-90 um, $N=3, a=2.5 \mathrm{~mm}$; (c) $90-125 \mu \mathrm{m}, N=1, a=1.0 \mathrm{~mm}$; (d) 90-125 $\mu \mathrm{m}, N=3, a=1.5 \mathrm{~mm}$.

concentrations at corners can promote their formation and growth. In the current work, most of the cracks had profiles that could be approximated as quarter circular cracks (Figures 6(a)-6(d)). Hence, the stress intensity factor, $K$, along the crack front can be estimated from [25]:

$$
K=\frac{2}{\pi} \sigma \sqrt{\pi a},
$$

where $\sigma$ is the remote applied stress and $a$ is the crack length. It is important to note here that this is an approximate solution for a quarter-circular crack in a half space. Hence, for semielliptical cracks or larger cracks that interact significantly with the specimen geometries, more complex solutions are needed, such as those published by Newman and Raju [24, 26] and Scott and Thorpe [27]. Finite width correction factors by Holdbrook and Dover [28] may also be applied to larger cracks. In any case, Equation (3a) may be rearranged to obtain estimates of the residual strength. This gives the following:

$$
\sigma_{f}=\frac{K_{\mathrm{Ic}}}{2 \sqrt{a / \pi}}
$$

where $\sigma_{f}$ is the fracture strength, $a$ is the crack length (due to thermal shock), and $K_{\mathrm{Ic}}$ is the stress intensity factor. The residual strengths of the thermally shocked samples were predicted using (3b). The values of the crack length, $a$, were obtained from SEM images of the fractured surfaces (Figure 6). It is important to note here that the crack lengths observed after the first quench cycle $(N=1)$ were larger $(a=1.3 \mathrm{~mm})$ in samples processed from finer particle sizes $(63-90 \mu \mathrm{m})$ than the crack lengths ( $a=1.0 \mathrm{~mm}$ ) observed in the samples processed from coarser particle sizes $(90-125 \mu \mathrm{m})$ for $N=1$. Further, the extent of shock-induced crack growth was greater in samples produced from finer particle sizes compared to the crack growth in samples produced from coarser particle sizes. This is shown in Figure 7 in which the measured crack lengths are plotted against the number of shock cycles for the porous clays that were examined in this study.

Figure 8 shows a plot of the predicted residual strengths $\left(\sigma_{f}\right)$ against the measured residual strengths obtained using (1). It can be seen that the predictions from (3b) are clearly in very good agreement with the measured residual strengths. 


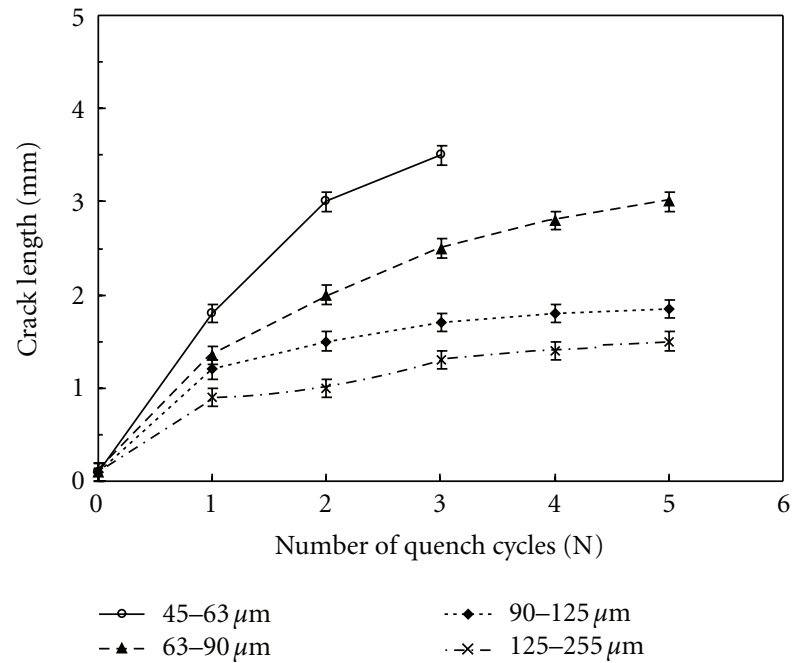

FIgURE 7: The measured crack lengths as a function of thermal quench cycles in the clay samples.

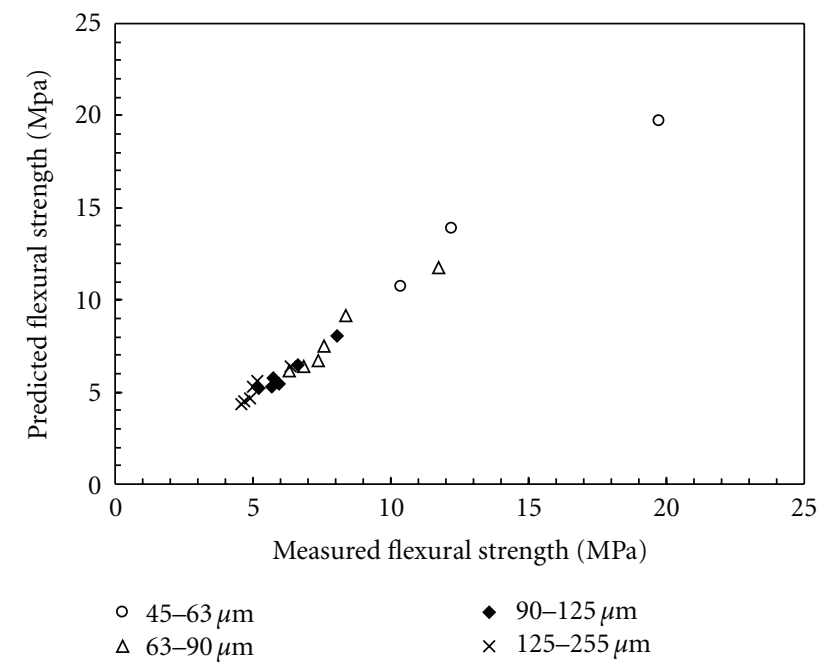

Figure 8: Comparison of the measured and predicted roomtemperature residual strengths of clay samples after thermal shock for $N=1-5$ thermal shock cycles.

4.2. Thermal Shock Resistance Parameters. Hasselman $R^{\prime \prime \prime}$ parameter $[1,29]$ characterizes the ability of a material to resist crack propagation under loading and further damage and loss of strength on thermal shocking. It is, therefore, of interest to explore the dependence of the $R^{\prime \prime \prime}$ parameter on pore size and the number of shock cycles. The $R^{\prime \prime \prime}$ parameter is related to the thermomechanical and elastic properties $(E, v)$ via [29]:

$$
R^{\prime \prime \prime}=\frac{E}{\sigma_{f}^{2}(1-\nu)},
$$

where $\sigma_{f}$ is the flexural strength (MOR), $E$ is Young's modulus, and $v$ is Poisson's ratio.

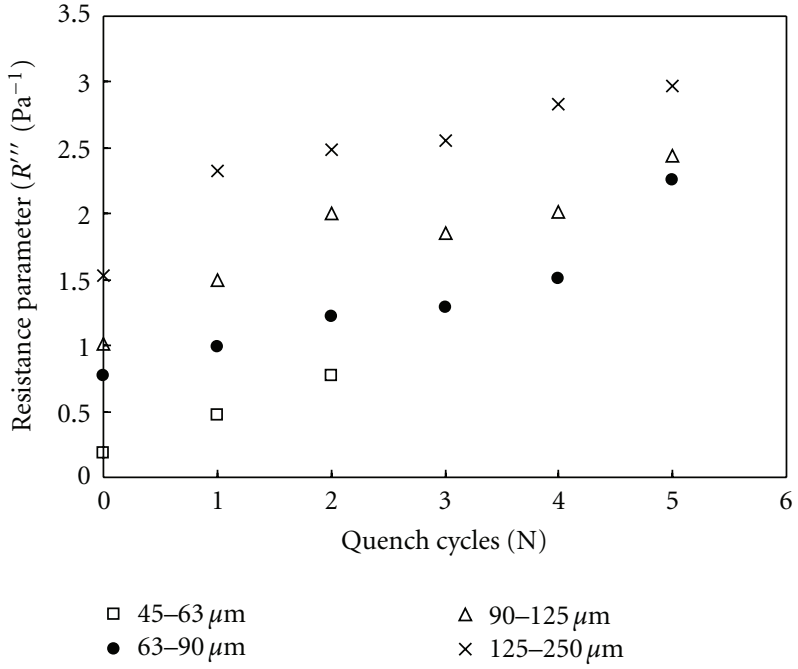

FIGURE 9: The thermal shock resistance parameter $R^{\prime \prime \prime}$ as function of Thermal Quench Cycles (N).

In the current work, Young's modulus, $E(P)$ at porosity $P$, was estimated from the analytical expression derived by Boccaccini et al. [22]. This accounts for the effects of pore shape and pore orientation on Young's modulus. It is given by [22]:

$$
E(P)=E_{o}\left(1-P^{2 / 3}\right)^{s},
$$

where $E_{o}$ is Young's modulus for zero porosity and $s$ is given by

$$
s=1.21 \alpha^{1 / 3} \sqrt{\left[1+\left(\frac{1}{\alpha^{2}}-1\right) \cos ^{2} \phi\right]} .
$$

In the above expression, $\alpha$ is the mean aspect ratio (shape factor) of the pores and $\cos ^{2} \phi$ represents the orientation factor of the pores, with $\phi$ being the angle between the rotational axis of the pores and the stress direction. The case of random statistical orientation is obtained by setting $\cos ^{2} \phi=0.33$.

From the SEM micrographs (Figures 1(a) and 1(b)), it is clear that the pores in the clay samples were mostly randomly oriented. Hence, it is justified to use a value of $\cos ^{2} \phi=0.33$ and $\alpha=0.4[22,30]$ in calculating the value of $s$. From the literature [30], the value of $E_{o}$ is $65.0 \mathrm{GPa}$ while the Poisson's ration $v$ is 0.23 . These were used in calculating $E(P)$. In this case, it was assumed that porosity and pore shape have a negligible effect on Poisson's ratio such that $v(P)=v_{o}=0.23$ [31].

The thermal shock parameter calculated from (4)-(6) are plotted in Figure 9 as a function of the number of quench cycles, $N$. The porous clay samples clearly show an increase in the $R^{\prime \prime \prime}$ parameter with increasing number of cold-shock cycles. Furthermore, samples produced from coarser particle sizes $(125-255 \mu \mathrm{m})$ exhibit higher crack growth resistance than those obtained from finer particle size distributions $(45-63 \mu \mathrm{m})$. This observation is in agreement with Figure 7 
in which it was observed that the shock-induced crack growth was greater in samples produced from finer particle sizes compared to the crack growth in samples with coarser particle sizes. Since the $R^{\prime \prime \prime}$ parameter characterizes the ability of a material to resist crack propagation, the current results suggest that the coarser particle sizes should result in greater thermal shock resistance. However, it is also important to note that larger particle sizes and increased porosity give rise to lower residual strength levels (Figure 3), although the number of shock cycles to failure generally increases with increasing porosity arising from the sintering of larger particle sizes.

4.3. Implications. The implications of the current work are quite significant. First, the results show clearly that the thermal shock resistance, $R^{\prime \prime \prime}$ and the room-temperature residual strengths change with increasing pore volume fraction, which was controlled in the current study by the sintering of different particle size ranges. However, the trends in the $R^{\prime \prime \prime}$ parameter (Figure 9) are opposite to those in the room-temperature residual strengths obtained after cold thermal shock (Figure 3). This is due presumably to the different damage and shielding mechanisms that operate in the different temperature and loading regimes (Figures 4 and 5). Hence, comparison of thermal shock resistance should consider the underlying damage and crack-tip shielding mechanisms.

Furthermore, the good agreement between the residual strength measurements and the residual strength predictions (Figure 8) suggest that simple fracture mechanics and fractographic approaches may be used to estimate the residual strength levels. Furthermore, nondestructive surface inspections for corner cracks may also provide useful approaches to the life assessment and management of kilns that are used to process molten metal and ceramics in the trillion-dollar materials processing industry. Since the stoppage of production (required for kiln repair) results in millions of dollars of losses in lost revenue, the application of the methods proposed in this study could provide the basis for the improved management and design of kilns. The methods can also be applied to the modeling of thermal shock in a wide range of thermostructural applications in which damage can occur due to thermal shock.

\section{Conclusions}

This paper presents the results of combined experimental and theoretical study of damage due to thermal shock in porous clays. Salient conclusions arising from the study are summarized below.

(1) The Hasselman thermal shock resistance parameter, $R^{\prime \prime \prime}$, and the room-temperature residual strengths after thermal shock are strongly dependent on the volume fraction of porosity. The parameter $R^{\prime \prime \prime}$ increases with increasing porosity (volume fraction) and shock cycles while the room-temperature residual strengths decrease with increasing porosity fraction and shock cycles.
(2) The room-temperature residual strengths can be predicted from a simple fracture mechanics model that idealizes the corner cracks formed due to thermal shock as quarter-circular cracks in a half space. However, actual crack geometries should be considered when the cracks are not approximately semicircular. The models should also account for finite width effects when the crack sizes are large compared to the structural sizes.

(3) Viscoelastic crack bridging is the dominant crack-tip shielding mechanism under thermal shock loading of porous clays. The extent of viscoelastic bridging decreases with increased porosity and increasing shock cycles. Furthermore, the room-temperature residual strengths are dominated by the shielding due to ligament bridging. Lower shielding levels are associated with crack deflection and crack branching during room-temperature fracture and shockinduced crack growth.

\section{Acknowledgments}

The authors would like to thank the National Science Foundation (Grant no. DMR 0231418) for the financial support. Appreciation is due to the Program Manager, Dr. Carmen Huber, for her encouragement and support.

\section{References}

[1] D. P. H. Hasselman, "Unified theory of thermal shock fracture initiation and crack propagation in brittle ceramics," Journal of the American Ceramic Society, vol. 52, no. 11, pp. 600-604, 1969.

[2] D. P. H. Hasselman, "Strength behavior of polycrystalline alumina subjected to thermal shock," Journal of the American Ceramic Society, vol. 53, no. 9, pp. 490-495, 1970.

[3] D. R. Larson, J. A. Coppola, and D. P. H. Hasselman, "Fracture toughness and spalling behavior of high- $\mathrm{Al}_{2} \mathrm{O}_{3}$ refractories," Journal of the American Ceramic Society, vol. 57, no. 10, pp. 417-421, 1974.

[4] L. Wang, J. L. Shi, M. T. Lin, H. R. Chen, and D. S. Yan, "The thermal shock behavior of alumina-copper composite," Materials Research Bulletin, vol. 36, no. 5-6, pp. 925-932, 2001.

[5] S. Zhu, S. Ding, H. Xi, Q. Li, and R. Wang, "Preparation and characterization of SiC/cordierite composite porous ceramics," Ceramics International, vol. 33, no. 1, pp. 115-118, 2007.

[6] A. G. Evans and E. A. Charles, "Structural integrity in severe thermal shock environments," Journal of the American Ceramic Society, vol. 60, no. 1-2, pp. 22-28, 1977.

[7] D. P. Marshall and M. V. Swain, "Crack resistance Curves in Magnesia-Partially-stabilized Zirconia," Journal of the American Ceramic Society, vol. 71, no. 6, pp. 399-407, 1988.

[8] R. Steinbrech, R. Khehans, and W. Schaarwächter, "Increase of crack resistance during slow crack growth in $\mathrm{Al}_{2} \mathrm{O}_{3}$ bend specimens," Journal of Materials Science, vol. 18, no. 1, pp. 265270, 1983.

[9] M. Saadaoui, C. Olagnon, and G. Fantozzi, "Evaluation of short crack R-curve behaviour of alumina under thermal shock loading," Journal of Materials Science Letters, vol. 15, no. 1, pp. 64-66, 1996. 
[10] J. Li, H. Y. Gong, R. X. Shi, and Y. S. Yin, "Rising crack-growthresistance behavior of $\mathrm{Al}_{2} \mathrm{O}_{3}$ based composites toughened with $\mathrm{FeAl}_{3}$ intermetallic," Ceramics International, vol. 33, no. 5, pp. 811-814, 2007.

[11] M. V. Swain, "R-curve behaviour in ceramics materials," in Advanced Ceramics II, S. Somiya, Ed., pp. 45-67, Elsevier Applied Science, Barking, UK, 1988.

[12] T. J. Lu and N. A. Fleck, "The thermal shock resistance of solids," Acta Materialia, vol. 46, no. 13, pp. 4755-4768, 1998.

[13] W. O. Soboyejo, C. Mercer, J. Schymanski, and S. R. Van Der Laan, "Investigation of thermal shock in a high-temperature refractory ceramic: a fracture mechanics approach," Journal of the American Ceramic Society, vol. 84, no. 6, pp. 1309-1314, 2001.

[14] T. J. Baker, J. Zimba, E. T. Akpan, I. Bashir, C. T. Watola, and W. O. Soboyejo, "Viscoelastic toughening of aluminosilicate refractory ceramics," Acta Materialia, vol. 54, no. 10, pp. 2665 2675, 2006.

[15] G. A. Gogotsi, "Thermal-shock resistance of heterogeneous ceramics and refractories," Refractories, vol. 34, no. 11-12, pp. 539-547, 1993.

[16] S. K. Obwoya, T. Baker, and W. Soboyejo, "Particle size and the mechanical properties of uganda clay," Materials and Manufacturing Processes, vol. 22, no. 2, pp. 206-213, 2007.

[17] W. D. Kingery, H. K. Bowen, and D. R. Uhlmann, Introduction to Ceramics, John Wiley \& Sons, Singapore, 2nd edition, 1991.

[18] M. Saadaoui, G. Orange, C. Olagnon, and G. Fantozzi, “Crack resistance curves of ceramics determined on notched and precracked bend bars," Journal of Materials Science Letters, vol. 10, no. 18, pp. 1090-1092, 1991.

[19] ASTME 399-90, Standard Test Method for Plane Fracture Toughness of Metallic Materials, American Society Testing and Materials, Philadelphia, Pa, USA, 1990.

[20] F. P. Knudsen, "Dependence of mechanical strength of brittle polycrystalline specimens on porosity and grain size," Journal of the American Ceramic Society, vol. 42, pp. 366-387, 1959.

[21] A. S. Wagh, R. B. Poeppel, and J. P. Singh, "Open pore description of mechanical properties of ceramics," Journal of Materials Science, vol. 26, no. 14, pp. 3862-3868, 1991.

[22] R. Boccaccini and G. Ondracek, "On the porosity dependence of the fracture strength of ceramics," in Third Euro-Ceramics, Engineering Ceramics, P. Duran and J. F. Fernndez, Eds., vol. 3, pp. 895-900, 1993.

[23] A. R. Boccaccini, "Influence of stress concentrations on the mechanical property-porosity correlation in porous materials," Journal of Materials Science Letters, vol. 17, no. 15, pp. 1273-1275, 1998.

[24] J. C. Newman and I. S. Raju, "An empirical stress-intensity factor equation for the surface crack," Engineering Fracture Mechanics, vol. 15, no. 1-2, pp. 185-192, 1981.

[25] M. V. Swain, "R-curve behavior and thermal shock resistance of ceramics," Journal of the American Ceramic Society, vol. 73, no. 3, pp. 621-628, 1990.

[26] I. S. Raju and J. C. Newman, "Improved stress- intensity factors for semi-elliptical surface cracks in finite thickness Plates," Struct Anal of Steel React Pressure Vessels, 1977.

[27] P. M. Scott and T. W. Thorpe, "A critical review of crack tip stressintensity factors for semi-elliptic cracks," Fatigue of Engineering Materials and Structures, vol. 4, no. 4, pp. 291-309, 1981.
[28] S. J. Holdbrook and W. D. Dover, "The stress intensity factor for a deep surface crack in a finite plate," Engineering Fracture Mechanics, vol. 12, no. 3, pp. 347-364, 1979.

[29] D. P. H. Hasselman, "Stress resistance parameters for Brittle refractory ceramics: a compendium," American Ceramic Society Bulletin, vol. 49, no. 12, pp. 1033-1037, 1970.

[30] B. O. Aduda and F. W. Nyongesa, "Role of aspect ratio in elastic modulus-porosity relationship of triaxial porcelain," British Ceramic Transactions, vol. 99, no. 5, pp. 206-211, 2000.

[31] V. A. Shutilov, Fundamental physics of Ultrasound, Gordon and Breach Science, New York, NY, USA, 1998. 

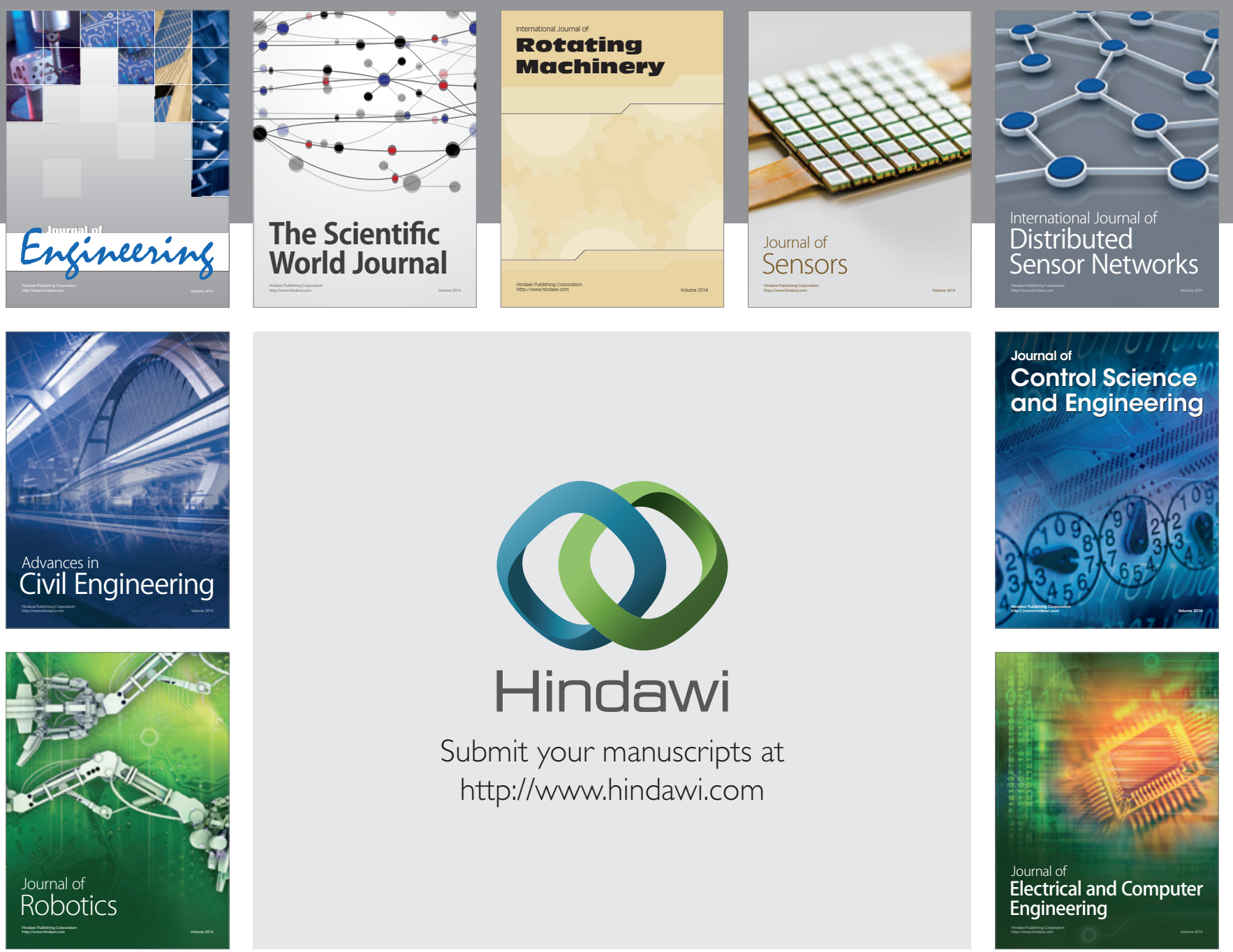

Submit your manuscripts at

http://www.hindawi.com
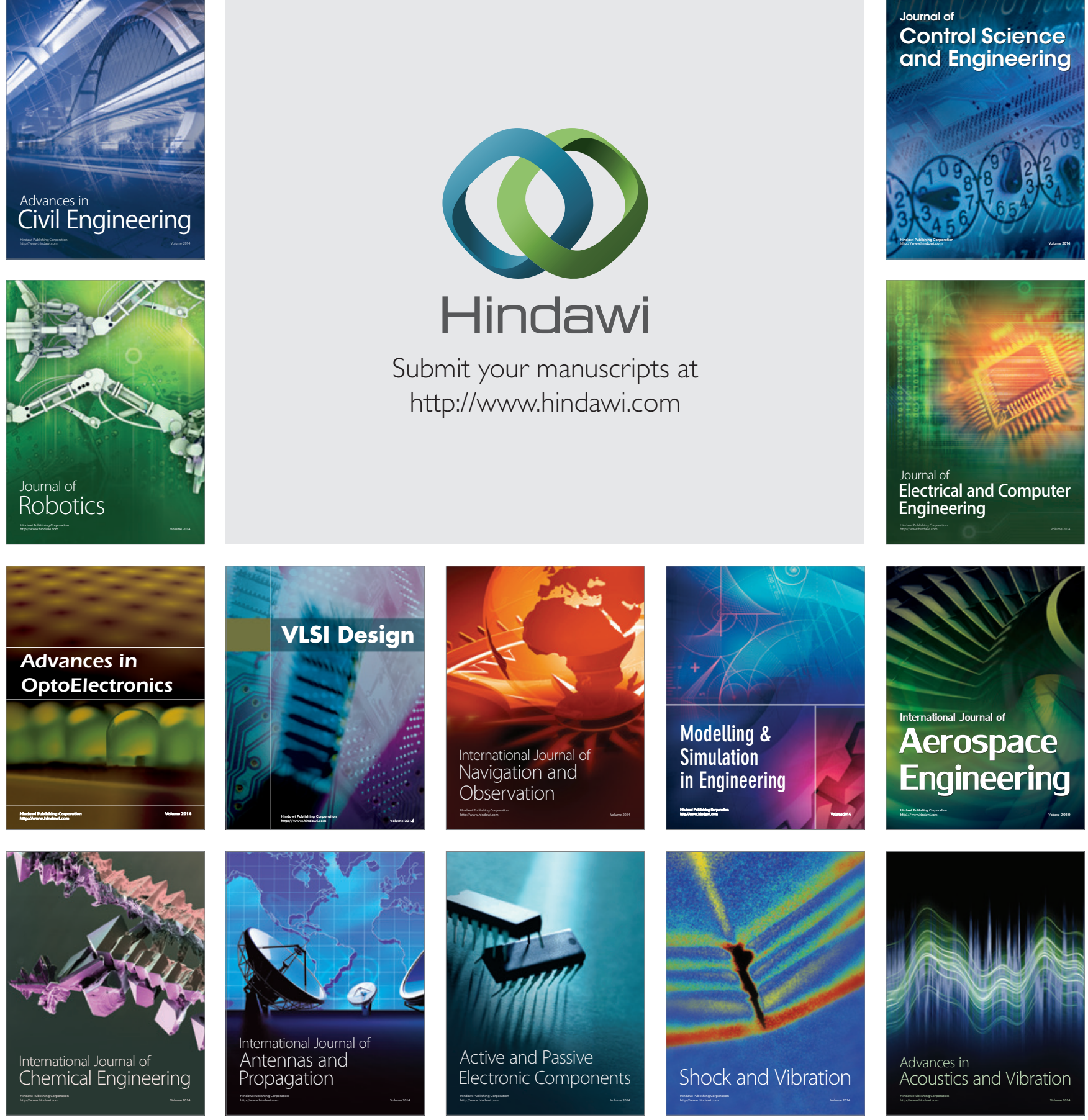